\title{
Medical History of Meat Handlers and the Occurrence of Zoonotic Mycobacterium bovis Infection in Imo State, Nigeria
}

\author{
I. D. Stan-Ekezie ${ }^{1 *}$, O. C. Abanobi ${ }^{1}$, C. I. C. Ebirim ${ }^{1}$, Sally lbe ${ }^{1}$ \\ and G. U. Onyeugo ${ }^{1}$ \\ ${ }^{1}$ Department of Public Health, Federal University of Technology, Owerri, Nigeria. \\ Authors' contributions
}

This work was carried out in collaboration among all authors. All authors read and approved the final manuscript.

Article Information

DOI: 10.9734/ARRB/2019/v34i330153

Editor(s):

(1) Prof. Ibrahim Farah, Professor of Biology/Environmental Health and Director of Animal Core Facilities, Department of Biology, Jackson State University, Mississippi, USA. (2) Dr. Bechan Sharma, Department of Biochemistry, University of Allahabad, Allahabad, India. (3) Paola Angelini, Department of Applied Biology, University of Perugia, Perugia, Italy. Reviewers:

(1) Wafaa Abd El-Ghany Abd El-Ghany, Cairo University, Egypt. (2) Philip Asumang, Kwame Nkrumah University of Science and Technology, Ghana. (3) Rojan Dahal, Nepal. Complete Peer review History: http://www.sdiarticle4.com/review-history/53802

Original Research Article

Received 25 November 2019

Accepted 30 January 2020

Published 06 February 2020

\section{ABSTRACT}

A study on the medical history of meat handlers and the occurrence of zoonotic Mycobacterium bovis infection in Imo State, Nigeria was carried out using one thousand two hundred respondents. A cross sectional survey was carried out in the three (3) senatorial zones Imo state Nigerian and a multistage sampling technique was used to choose the abattoirs under study. A well structured questionnaire was distributed and the data analyzed. Results showed lack of BCG awareness $(O R=0.174 ; P=0.017)$ to be statistically significant to the occurrence of bovine $T B$, on the other hand the range of the various times respondents go for medical checkups was considered; those who often attend medical checkup against those who always go for medical checkup (OR=16.187; $\mathbf{P}=<\mathbf{0 . 0 0 0 1}$ ), also those who never go for medical checkup against those that had medical checkup three months ago $(O R=1.910 ; P=<0.001)$. It was observed in this study that lack of $B C G$ awareness and the care free attitude to medical checkup pose as a risk factor to Mycobacterium bovis T.B 
among meat handlers. Therefore, there is need to initiate an awareness program on the importance of BCG intake in the fight against Mycobacterium bovis T.B and improve existing diagnostic test to specifically deter early phase of the infection.

Keywords: Abattoir; bovine; zoonoses; tuberculosis; Odd Ratio (OR).

\section{INTRODUCTION}

There is increasing prevalence of unregulated and insanitary contact between humans and animals worldwide due to increasing population density and growth especially in developing countries where livestock offers important socioeconomic, cultural and religious pathway out of poverty [1]. The world Health Organization(WHO) estimated that in 2014 human TB incidence and mortality was 9.6 million and 1.5 million respectively [2] The prevalence of bovine tuberculosis(Btb) in some developing countries cannot be overemphasized in Mozambique, it is estimated to be $39.6 \%$ [3]. Whereas in Nigeria, the prevalence of bovine tuberculosis due to Mycobacterium ranges from 2.5 percent in 1970 to 14 percent in 2007. M. bovis has been a historical source of tuberculosis in human infection through drinking of contaminated unpasteurized milk or inhaling aerosols produced by diseased farm animals [4] and through consumption of improperly cooked infected meat and meat products [5,6]. The prevalence of tuberculosis is high, with the abattoir workers, cattle merchants and farm dealers being the group most exposed to the infection [7] it is imperative to understand that prior to the sale, cattle are raised and fattened in close proximity to farmer's home, after being sold to cattle merchants, they are kept within the vicinity of the merchants before being sold to butchers. These butchers, who spend greater hours at the abattoirs and the veterinary officers due to the nature of the work thereby, have ample opportunity for zoonotic transmission of infection [8]. They also eat with same hands due to poor food habits thereby ingesting the mycobacterium along with their food [9]. Recent study reported an association of bovine tuberculosis infection with non-vaccination of children with BCG, age, gender, physiological status and husbandry practices such as cattle movement and contact with wildlife, hence complicating the morbidity and mortality of tuberculosis cases [10]. The increase in human tuberculosis could be attributed to medical history, poverty, ignorance and lack of health facilities for routine health checks of farmers and abattoir workers [11].
In view of the above, this study is designed to determine the medical history of meat handlers with the occurrence of zoonotic Mycobacterium bovis infection in Imo State, Nigeria. The study highlights loopholes in the medical history of meat handlers and the demographic characteristics of these meat handlers in Imo State. The findings of this study would reveal the relationship between the medical history of meat handlers and the various demographic exposures that led to the occurrence of Mycobacterium bovis infection.

\section{MATERIALS AND METHODS}

A cross sectional survey design was used. Multistage sampling technique was used to select 1200 study participants; also a well structured questionnaire was used to determine the relationship between medical histories of meat handlers with the occurrence of Bovine TB in Imo State.

An informed consent was obtained from each respondent before data was collected and Ethical clearance was obtained from the gate keepers of the abattoirs. The data was analyzed using Statistical Package for Social Science (SPSS) version 20.0 computer software. The results were presented using simple frequency and percentages. Odd-ratio was used to test for the relationship between variables of interest and the occurrence of Bovine TB. P-value $<0.05$ was considered statistically significant.

\subsection{Method of Data Analysis}

Data was analyzed using the Statistical Package for Social Sciences (SPSS) version 20.0 for both descriptive and inferential statistical analysis of variables. The analysis of the data was done in stepwise manner; bivariate and multivariate analyses using the logistic regression models to find the odds ratio for the association between risk factors and bovine TB. In the bivariate analysis, variables with $p$-value $\leq 0.25$ [12] and those of known plausible biological contribution for bovine TB positivity such as age were subjected to Multivariate analysis to control for confounding and effect modification. Quantitative 
data was analyzed descriptively using frequencies, mean and standard deviation. Also bar charts were used to present the frequencies. Data was also analyzed at $95 \%$ Confidence Interval and results were considered significant at $p$-value $\leq 0.05$.

\section{Inclusion criteria}

1) All meat handlers who are 18years and above present at the abattoir at the time, the study was carried out.

2) All meat handlers that gave their consent to the study.

\section{Exclusion criteria}

1) Meat handlers below 18 years of age.

2) All individuals at the abattoirs at the time this study was carried out who are not meat handlers.

3) Meat handlers' present but did not consent to the study.

\section{RESULTS}

\subsection{Demographic Characteristics of meat handlers in Imo State}

Out of the 1,200 subjects that responded, $592(49.3 \%)$ were between $41-60$ years old, $563(46.9 \%)$ were between $20-40$ years old, $33(2.8 \%)$ were above 60 years old, while $12(1.0 \%)$ were less than 20 years of age. The mean age of the respondents is 41.0 years (see Table 1).

On the account of their sex, $965(80.4 \%)$ of them were males while $235(19.6 \%)$ of them were females (See Table 1).

Based on their educational status, those that have secondary education were 605(50.4\%), those that have primary level of education were $336(28.0 \%)$, while $259(21.6 \%)$ have tertiary level of education (see Table 1).

Based on their occupation, Meat vendors $568(47.3 \%)$, Butcher 451(37.6\%), Transporters $164(13.7 \%)$, Veterinary attendants $17(1.4 \%)$.

With regards to the time frame of working in the abattoir, $617(51.4 \%)$ have spent more than 10 years working in the abattoir, $550(45.8 \%)$ have spent between 1-10 years in the abattoir, $33(2.8 \%)$ have spent less than one year working in the abattoir, while. The mean length of time worked in the abattoir by the respondents is 18.2 years (see Table 1).

Table 1. Responses of subjects by sociodemographic characteristics $(n=1,200)$

\begin{tabular}{|c|c|c|}
\hline Variable & Frequency & Percentage (\%) \\
\hline \multicolumn{3}{|c|}{$\begin{array}{l}\text { Age of respondents } \\
(41.0 \pm 11.6)\end{array}$} \\
\hline$<20 y r s$ & 12 & 1.0 \\
\hline $20-40$ yrs & 563 & 46.9 \\
\hline $41-60$ yrs & 592 & 49.3 \\
\hline Above 60 yrs & 33 & 2.8 \\
\hline \multicolumn{3}{|l|}{ Sex } \\
\hline Male & 965 & 80.4 \\
\hline Female & 235 & 19.6 \\
\hline \multicolumn{3}{|c|}{ Marital status } \\
\hline Single & 190 & 15.8 \\
\hline Married & 888 & 74.0 \\
\hline Divorced & 22 & 1.8 \\
\hline Separated & 66 & 5.5 \\
\hline Widow & 34 & 2.8 \\
\hline \multicolumn{3}{|c|}{ Educational qualification } \\
\hline Primary & 336 & 28.0 \\
\hline Secondary & 605 & 50.4 \\
\hline Tertiary & 259 & 21.6 \\
\hline \multicolumn{3}{|l|}{ Occupation } \\
\hline Butchers & 451 & 37.6 \\
\hline $\begin{array}{l}\text { Meat } \\
\text { vendors }\end{array}$ & 568 & 47.3 \\
\hline Veterinary & 17 & 1.4 \\
\hline Attendants & & \\
\hline $\begin{array}{l}\text { Meat } \\
\text { transporters }\end{array}$ & 164 & 13.7 \\
\hline \multicolumn{3}{|c|}{$\begin{array}{l}\text { Length of time worked at the abattoir } \\
(18.2 \pm 12.7)\end{array}$} \\
\hline$<1 \mathrm{yr}$ & 33 & 2.8 \\
\hline $1-10 \mathrm{yrs}$ & 550 & 45.8 \\
\hline Above 10yrs & 617 & 51.4 \\
\hline \multicolumn{3}{|c|}{$\begin{array}{l}\text { Number of family members at home } \\
(6.9 \pm 2.8)\end{array}$} \\
\hline$<5$ persons & 201 & 16.8 \\
\hline $5-10$ persons & 944 & 78.7 \\
\hline $\begin{array}{l}\text { Above } \\
\text { 10persons }\end{array}$ & 55 & 4.6 \\
\hline
\end{tabular}

With regards to the household number, $944(78.7 \%)$ of them live with about $5-10$ persons, $201(16.8 \%)$ of the study subjects live with less than 5 persons in their residents, while 55(4.6\%) of them live with more than 10 persons in their homes. The mean number of persons living with the respondents is 6.9persons (see Table 1). 


\subsection{Distribution Based on the Medical History of Respondents}

Out of the 1200 respondents, Most of them 1099 $(91.6 \%)$ were aware of BCG, while 101(8.4\%) are not aware.

Based on being vaccinated with BCG, 995(82.9\%) had BCG vaccination during their childhood, while $205 \quad(17.1 \%)$ were not vaccinated with BCG during their childhood.

With respect to having long lasted or bloody cough, Most of them 1046(87.2\%) have not had long lasted or bloody cough, while 154 (12.8\%) have had long lasted or bloody cough.

Results from Bovine TB treatment of household members, most of the respondents 1156 (96.3\%) revealed that none of their family members have had Bovine TB treatment, while $44(3.7 \%)$ have had family members who had taken Bovine TB treatment.

With respect to frequency of their medical checkups, most of the respondents 585 (48.8\%) often go for medical check-ups, $478(39.8 \%)$ never go for medical check-ups and $137(11.4 \%)$ frequently go for medical check-ups.
Results from time -frame of respondent's last TB test, most of them $830(69.2 \%)$ had never ran a TB test, 179(14.9\%) had TB test a year ago, $79(6.6 \%)$ had TB test 6 months ago and $56(4.7 \%$ ) had TB test 3 months ago (see Fig. 1).

Table 2. Responses of subjects with respect to medical history $(n=1,200)$

\begin{tabular}{|c|c|c|}
\hline Variable & Frequency & Percentage \\
\hline \multicolumn{3}{|c|}{ Awareness of BCG } \\
\hline Yes & 1099 & 91.6 \\
\hline No & 101 & 8.4 \\
\hline \multicolumn{3}{|c|}{ BCG vaccination during childhood } \\
\hline Yes & 995 & 82.9 \\
\hline No & 205 & 17.1 \\
\hline \multicolumn{3}{|c|}{ Cough duration if yes } \\
\hline 1 month & 44 & 3.7 \\
\hline 3 months & 55 & 4.6 \\
\hline None & 1101 & 91.8 \\
\hline \multicolumn{3}{|c|}{ BTB treatment of any family member } \\
\hline Yes & 44 & 3.7 \\
\hline No & 1156 & 96.3 \\
\hline \multicolumn{3}{|c|}{ Frequency of medical checkup } \\
\hline Always & 137 & 11.4 \\
\hline Sometimes & 585 & 48.8 \\
\hline Never & 478 & 39.8 \\
\hline
\end{tabular}

Table 3. Bivariate analysis of the relationship between vaccination status of butchers and abattoir workers and the occurrence of bovine TB

\begin{tabular}{lllll}
\hline S/N & Variable & $\begin{array}{l}\text { Odds ratio } \\
\text { (OR) }\end{array}$ & $\begin{array}{l}\text { Confidence interval } \\
\text { (Cl): (95\%) }\end{array}$ & P-value \\
\hline 1. & BCG awareness & 0.174 & $0.041-0.730$ & $0.017^{*}$ \\
2. & BCG vaccination of family members & 0.841 & $0.478-1.482$ & 0.550 \\
3 & Frequency of medical check-ups & & & 0.0001 \\
\hline A. & Often/Always & 16.187 & $5.278-49.637$ & 0.0001 \\
B & Never/3months ago & 1.910 & $1.642-2.221$ & \\
\hline
\end{tabular}

Table 4. Multivariate analysis of the relationship between bovine tuberculosis and risk factors

\begin{tabular}{lllll}
\hline S/N & Variable & $\begin{array}{l}\text { Odds ratio } \\
\text { (OR) }\end{array}$ & $\begin{array}{l}\text { Confidence } \\
\text { interval (Cl): 95\% }\end{array}$ & $\begin{array}{l}\text { P. } \\
\text { Value }\end{array}$ \\
\hline 1 & No BCG awareness & 0.096 & $0.027-0.336$ & 0.0001 \\
2 & Gender (male) & 2.405 & $1.368-4.227$ & $0.002^{*}$ \\
3 & Frequency of medical check-up (sometimes) & 0.899 & $0.567-1.425$ & 0.650 \\
4 & Age of respondent ( $\geq 20 y r s /<20 y r s)$ & 2.390 & $0.641-8.906$ & 0.194 \\
5 & Last medical check-up (never/3months ago) & 11.292 & $4.622-27.587$ & 0.0001 \\
6 & Number of household members $(>5 /<5)$ & 1.543 & $0.424-5.613$ & 0.511 \\
\hline \multicolumn{5}{c}{${ }^{*}$ Values that remained significant at $\leq 0.05$ after the unconditional logistic regression model }
\end{tabular}




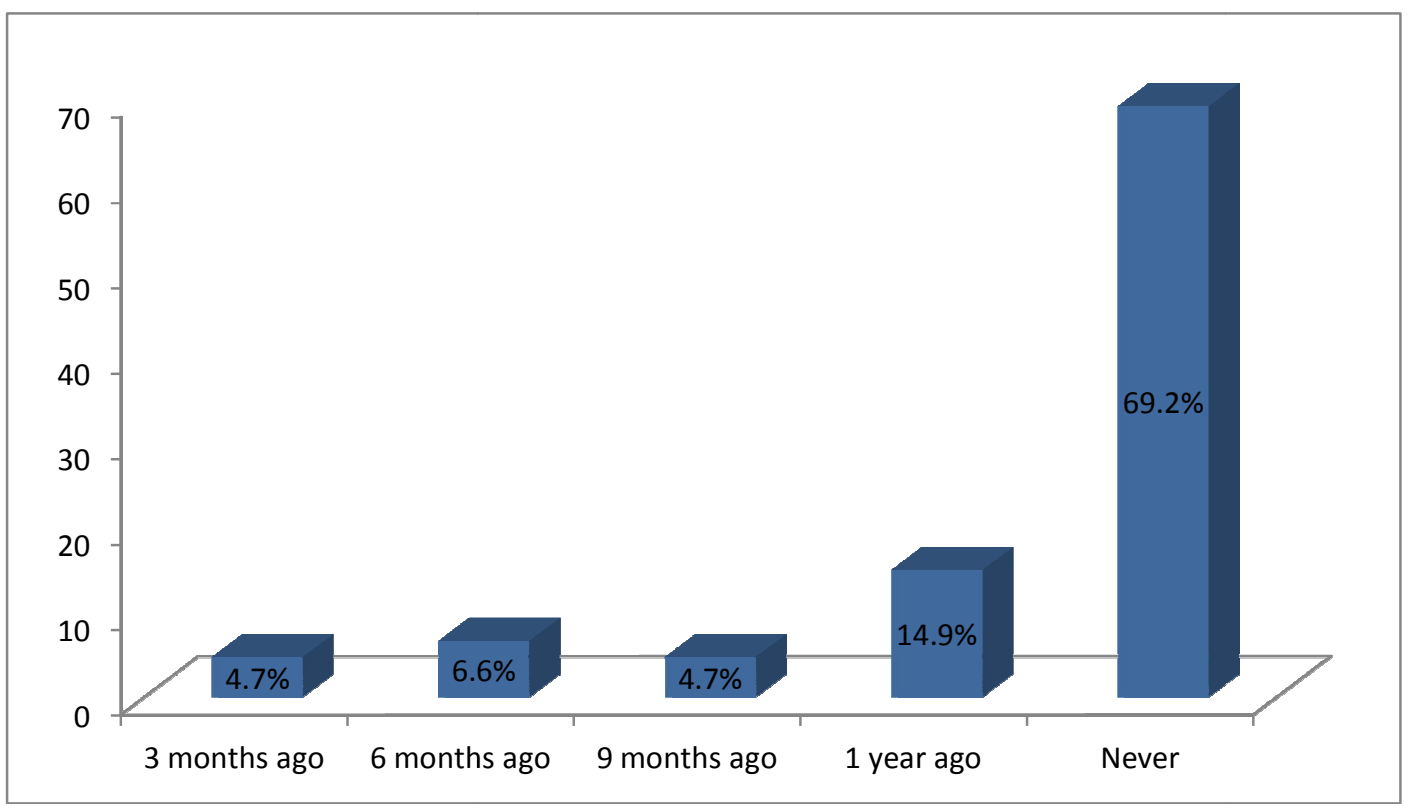

Fig. 1. The last TB test done by the subjects

3.3 Bivariate Analysis of the Relationship between Medical Histories of Meat Handlers and the Occurrence of Bovine TB

When BCG awareness, was considered as a risk factor for bovine TB, result revealed (OR=0.174; $\mathrm{p}=\mathbf{0 . 0 1 7}$ ), hence lack of BCG awareness was statistically significant to the occurrence of bovine TB, this was in accordance with the study hypotheses. In the same vein, BCG vaccination of respondents has a protective effect on the occurrence of bovine TB $(\mathrm{OR}=0.841 \mathrm{P}=0.550)$ and this was keeping with previous study which stated that no BCG vaccination was 0.7 times associated with increased risk of exposure than those that have been vaccinated [10]. It also confirmed the previous study of Shitaye et al. [11]. that in general, tuberculosis can be effectively controlled through BCG vaccination.

Based on frequency of medical check-ups, the range of the various times respondents go for medical check-ups was considered as a risk factor; those that often go for medical check-ups against those that always go for medical checkups, the result revealed (OR=16.187; $P=<0.001)$, hence, it states that often times medical checkups by meat handlers is statistically significant to the occurrence of bovine TB.

Also those that never go for medical check-up against those that had medical check-up 3 months ago, the result revealed (OR=1.910; $\mathbf{p}=<0.001$ ), hence it states that never attended medical check-ups by meat handlers is statistically significant to the occurrence of bovine TB.

\subsection{Multivariate Analysis of the Relationship between Bovine Tuberculosis and Risk Factors}

After the unconditional logistic regression model, factors such as Lack of BCG awareness (OR= 0.096; $\mathrm{Cl}=0.027-0.336 ; \mathrm{P}=0.0001)$, Gender (male) $(\mathrm{OR}=2.405 ; \mathrm{Cl}=1.368-4.227 ; \mathrm{P}=0.002)$ and Last medical check-up (never) $(\mathrm{OR}=11.292$; $\mathrm{Cl}=4.622-27.587 ; \quad \mathrm{P}=0.0001)$ remained statistically significant among all factors that were significant at the bivariate analysis.

\section{DISCUSSION}

Findings from the study revealed that, $80.4 \%$ of the respondents were males while $1.96 \%$ of them were females, this however is in accordance with the study of Hambuolu et al. [12] which showed that abattoir workers are dominated by males in the middle age group.

Findings of the study also revealed that, $16.8 \%$ of the respondents lived with $<5$ resident members at home, $78.7 \%$ of them lived with between 5-10 household members, while $4.6 \%$ of them lived with more than 10 household 
members, this agrees with the study of Ndukum et al. [13] in Cameron that urban and peri-urban (compared to rural) livestock farming is fastgrowing but most livestock professionals and handlers in Cameroun are small-scale farmers, nomads, herders, wage labourers and unemployed youths who are also poor and uneducated.

Findings from the study revealed that, BCG awareness havepositive effect on the occurrence of bovine TB, this aligns with what was reported by Sa'idu et al. [9] in Bauchi, Nigeria, where $90.3 \%$ of the respondents were aware of the zoonotic nature of bTB.

Findings from this study also revealed that,BCG vaccination of respondents has a protective effect on the occurrence of bovine TB $(O R=0.841 \mathrm{P}=0.550)$ and this aligns with the study of Kachalla, 2014a [10], that no BCG vaccination was 0.7 times associated with increased risk of exposure than those that have been vaccinated. It also confirmed the previous study of Shitaye et al. 2007a [11] that in general, tuberculosis can be effectively controlled through $B G C$ vaccination.

Findings from the study also revealed that the diverse time range of medical check-ups showed strong statistical significance $P=0.0001$ with the occurrence of bovine TB.

\section{CONCLUSION}

This study has revealed factors such as masculinity, BCG unawareness and never going for medical check-up may promote bovine TB occurrence on butchers and abattoir workers. There is therefore need to initiate awareness campaign capturing enlightenment on these areas of deficiencies. This campaign should involve both governmental and nongovernmental organizations and should also not be limited to only people in this occupation so as to reduce the risk of transmission of BTB within and outside this group of workers in Imo State, Nigeria.

\section{CONSENT AND ETHICAL APPROVAL}

A letter of introduction was obtained from the Department of Public Health, Federal University of Technology Owerri and was submitted to abattoir gate keepers. Ethical clearance was obtained from the gatekeepers of the abattoirs, the modalities for the survey were reached and days for data collection fixed. Informed consent was obtained from each eligible abattoir worker before questionnaire administration and sample collection was done. Confidentiality of information obtained was assured and maintained.

\section{COMPETING INTERESTS}

Authors have declared that no competing interests exist.

\section{REFERENCES}

1. Who Report. Global tuberculosis control: Epidemiology, strategy, financing. World Health Organization, Geneva, Switzerland; 2009.

2. World Health Organization for Animal Health; 2014.

3. The Ivaina Moiane, Adelina Machodo (...),Margarida Correia-Neres. Prevent tuberculosis and risk factors assessment in cattle in rural live stoct areas of Govuro District in the southeast of Mozambique. PLoS One. 9(3):e 91527.

DOI: 10.1371/journal. Pone.0091527

4. Allic-Beues C, Fqnville Dafanx M, Stoffls K, Ommeslap D, Walravents K, Saegeman C, et al. Important of identifying Mycobacterin boris asa conddive agent og human tuberculosis. Eur Respr J. 2010;35(3):6924.

5. Khattak MH, Mushtaq, Haider J. Zoonotic tuberculosis in occupationally exposed groups in Pakistan (occup.med (Lond). 2016;66(5):371-376.

[Published online 2016 mar 30]

DOI: 101093/occmed/kgw039

[PMCID: PMC 4913371, PMID 27032413]

6. Vayr F, Martin-blondel G, Savall F, Saulat JM, Deffontaines G, Herin F. Occupational exposure to human Mycobacterium boris infection: 4 systematic review plos Neg 1 Trop Dis. 2018;12(1).

7. Madsen JM, Zimmerrmann GN, Tiimmons J, Tablante NL. Avian influenza sero prevalence and bio security risk factors in Maryland backyard poultry: A crosssectional study. PLoS One. 2013;8(2):e56851.

8. Hambuolu D, Freeman J, Taddese HB. Predictors of bovine TB risk behaviour amongst meat handlers in Nigeria: A cross-sectional study guided by the health belief model. Plos One. 2013;8(2):e56091.

9. Ndukum JA, Kudi AC, Bradley G, AneAnyangwe IN, Fon-Tebug S, Tchoumboue 
J. Prevalence of bovine tuberculosis in abattoirs of the littoral and western highland regions of Cameroon: A cause for public health concern; 2010.

10. Sa'idu AS, Okolocha EC, Dzikwi AA, Gamawa AA, Ibrahim S, Kwaga JKP, Usman A, Maigari SA. Public health implications and risk factors assessment of Mycobacterium bovis infections among abattoir personnel in Bauchi State, Nigeria. Journal of Veterinary Medicine. 2015;1-5.
[Article ID718193]

11. Kachalla MG. Prevalence of bovine tuberculosis and knowledge, attitude and practice of workers in two Abuja abattoirs, Federal Capital Territory, Nigeria. A thesis submitted to the postgraduate school, Ahmadu Bello University, Zaria; 2014.

12. Shitaye JE, Tsegaye W, Pavlik I. Bovine tuberculosis infection in animal and human populations in Ethiopia: A review. Veterinarni Medicina. 2007;52(8):317-332.

(c) 2019 Stan-Ekezie et al.; This is an Open Access article distributed under the terms of the Creative Commons Attribution License (http://creativecommons.org/licenses/by/4.0), which permits unrestricted use, distribution, and reproduction in any medium, provided the original work is properly cited.

Peer-review history:

The peer review history for this paper can be accessed here: http://www.sdiarticle4.com/review-history/53802 